\title{
CAPITULAÇÃO E MELANCOLIA
}

\section{0 narrador de Marcelo Mirisola}

\author{
JOANA A CONTRAGOSTO, \\ de Marcelo Mirisola. Rio de Janeiro: Record, 2005. \\ O AZUL DO FILHO MORTO, \\ de Marcelo Mirisola. São Paulo: Editora 34, 2002.
}

RICARDO LÍSIAS

[1] Este texto desenvolve muitos pontos do meu ensaio "Outras arrebentações", publicado como posfácio a Notas da arrebentação. Marcelo Mirisola. São Paulo: Editora 34, 2005.
Dos autores que constituíram uma obra recentemente, Marcelo Mirisola está entre os que criaram os narradores mais relevantes. Talvez seja por aí - sempre pela forma - que seenxergará uma tendência nascente na literatura brasileira contemporânea. As obras mais importantes apostam tudo no narrador. A pequenina novela "Acaju (a gênese do ferro quente)", publicada primeiro sob a forma de folhetim na revista Cult e depois recolhida no volume de esparsos Notas da arrebentação, é um bom exemplo dos procedimentos formais adotados por Mirisola. ${ }^{1}$ Já na primeira página, o narrador inicia seu hábito de escarnecer todo e qualquer detalhe que constitua a vida da personagem que será seu alvo, uma companheira de relacionamento, um amigo, vizinhos ou seja lá quem for. Aparece então uma listagem de mesquinharias, normalmente do gosto da nossa classe média. Em seguida o narrador desiste da crítica, sucumbe e admite desejar tudo o que estava criticando. A chave é clara: cria-se um universo de ridicularidades e quando ele está muito bem esquematizado, o narrador se alia a ele. De imediato, é desfeito o suposto ambiente de crítica que havia: o narrador é fraco a ponto de capitular perante toda a sordidez que ele mesmo revelava. Em "Acaju", a personagem Ana g.é o protótipo de tudo o que há de mais kitsch e boçal entre nós, no entanto o narrador a escolheu (dona de "brotoejas encantadoras") para ser a potencial mãe de sua filha.

A propósito, uma das imagens mais recorrentes na obra de Marcelo Mirisola é a singela figura de uma filha que o narrador, a todo instante, reitera nunca ter tido. Em diferentes situações, aparece uma criança bonita e doce que a covardia dos pais nunca deixa nascer. A outra ima- 
gem é a da abertura de buracos: o narrador, aqui e ali, sempre está cavando um. Evidentemente, trata-se de imagens que compõem o material com que Mirisola arquiteta o cenário em que seu narrador irá orquestrar notáveis capitulações. De um lado, criança nenhuma deve mesmo nascer diante da mesquinharia com que os sentimentos e situações são tratados; de outro, é preciso estar sempre se escondendo, nem que seja debaixo da terra, para suportar a vergonhosa covardia. O narrador de Marcelo Mirisola não procria e apenas reproduz, vezes sem conta, um vergonhoso universo de derrotas e desistências. Não éà toa, ainda, que toda relação sexual é submetida a um choque vocabular cujo objetivo, mais do que erotizar a situação ou mesmo criar pornografia (erotismo e pornografia que de resto não existem na obra de Marcelo Mirisola), é neutralizar o afeto em uma negociação mesquinha entre dois corpos que, de jeito nenhum, poderiam gerar uma criança, uma menina linda muito menos. A propósito - detalhe que vem se intensificando nos últimos livros - , tal neutralização afetiva conduz a um resultado quase lírico: por certo, há o impedimento de que a mesquinharia gere beleza. É fácil perceber, portanto, que Mirisola trabalha criando expectativas em negativo, por exemplo procurando um lirismo justamente na operação de impedi-lo de surgir em um universo sórdido e covarde. O narrador incapaz de enfrentar a mesquinharia e, ao contrário, sempre disposto a se aliar a ela não se permite, feito um pai zeloso, colocar uma criança nesse mundo. O narrador de Marcelo Mirisola é liricamente justo. Talvez seja essa sua única coragem, aliás, não muito grande. Mas extremamente digna.

Outro detalhe que salta aos olhos do leitor atento de Marcelo Mirisola é a melancolia. Ela está por toda parte e, muitas vezes, chega a ser uma das bases do texto. No romance $\mathrm{O}$ azul do filho morto, ${ }^{2}$ a melancolia é o motor que sustenta quase todas as situações. No caso da novela "Acaju", o sentimento melancólico não é construído de maneira diferente que do resto da obra de Mirisola: sempre há uma enumeração de hábitos e sentimentos pequenos e mesquinhos (e muitas vezes egoístas) que se associam, às vezes mais intensamente que outras, à memória de lugares, tampouco elegantes, que o narrador teria freqüentado durante as décadas de 1970 e 1980, momento por excelência em que se situa a memória do narrador de Marcelo Mirisola. A melancolia, portanto, surge justamente da associação da mesquinharia contemporânea, algo psicológica, com a mediocridade geográfica das lembranças. Estamos diante de um narrador que passou a infância, coincidentemente o tempo da ditadura militar, na ilha Porchat e nas praias da baixada santista. Naturalmente é preciso imaginação para encontrar algo mais cafona. Tal melancolia se alinha à propensão de capitular que já identificamos nesse narrador. Evidentemente, não estamos
[2] Cf. Marcelo Mirisola. O azul do filho morto. São Paulo: Editora 34, 2002 
[3] Cf.Ana Cristina César. A teus pés. São Paulo:Ática, 1999.

[4] Cf. Caio Fernando Abreu. MorangosMofados.São Paulo:Agir,2005. tomando o sentimento melancólico como algo positivo, até porque, para o narrador em questão, ele serve sempre como reforço para a denúncia da sua própria covardia: é sempre a lembrança kitsch que aparece. $O$ recurso, porém, denuncia a habilidade formal do autor, já que chama a atenção justamente para o aspecto da memória — um dos pilares da melancolia de Marcelo Mirisola. Cabe, ainda, investigar qual é a imagem que esse narrador tenta criar para as décadas de 1970 e 1980, no Brasil, tempo cuja escolha, evidentemente, não é nem um pouco ingênua.

De imediato, o nome Ana g., escolhido por Marcelo Mirisola para chamar a personagem principal de "Acaju" - e única, se não contarmos o narrador - , remete à poetisa Ana Cristina César, ícone da literatura brasileira da década de 1970. A novela cita, diretamente e por duas ou três vezes, o nome de Caio Fernando Abreu, contemporâneo de Ana Cristina, mas que acabou tendo uma vida um pouco mais longa.Ambos, por razões diferentes, morreram em circunstâncias trágicas e em um momento, também distinto para um e outro, particular da história brasileira. Para uma novela que, de cara, anuncia o assassinato de sua única personagem, o detalhe não é supérfluo e evidencia o propósito do autor de criar um narrador que se situe histórica e culturalmente de maneira muito bem definida. A referência a Caio Fernando Abreu e Ana Cristina César, ainda, fornece outros argumentos para a afirmação de que a melancolia, juntamente com o hábito da capitulação e muito por conta dele mesmo, é um dado certo na obra de Marcelo Mirisola. De um jeito ou de outro, e sempre respeitando a diferença de gêneros (principalmente no caso da poesia), não escapa a ninguém a enorme carga melancólica de livros como $A$ teus pés 3 e Morangos Mofados. ${ }^{4} \mathrm{Na}$ obra de Marcelo Mirisola, porém, a melancolia recoloca-se como uma das forças que constituem a impressão de decepção que constitui o narrador. Em Ana Cristina e Caio Fernando Abreu, ela fermentava um composto que pretendia construir uma espécie de sentimento coletivo e de época. O que houve, portanto, foi uma atilada operação literária: o que era dado de contexto tornou-se ferramenta formal. Marcelo Mirisola está retrabalhando nossa história, tornando-a elemento de estrutura. É desse jeito que seu narrador consegue fugir da banalização em que se pode escorregar na leitura dos melhores autores de nosso passado recente.

Evidentemente, não estou dizendo que Marcelo Mirisola continua a obra - ou mesmo faz parte de uma tradição - de Ana Cristina César e Caio Fernando Abreu. Não consigo achar nenhum bom argumento para sustentar essa afirmação. Creio, ao contrário, que a operação de tornar recurso formal o que era dado histórico (ou seja, matéria rigo- 
rosamente datada) fará com que enxerguemos com outros olhos os próprios Caio Fernando e Ana Cristina César. Claro que vale a pena estimar, a partir disso, qual a conseqüência dessa nova reorganização. Enfim, de cara é fácil ver que autores assim movem estruturas e, portanto, solidificam sua obra. No entanto, acho mais urgente apontar que a incompreensão do dado formal como ordem verdadeiramente de intervenção acaba banalizando o fazer artístico e tornando-o mera repetição de clichês - pois a história deslocada de seu momento torna-se apenas um encadeamento de chavões. Atualmente, a literatura brasileira assiste a uma espécie de reanimação do que se convencionou chamar movimento beat. O próprio Marcelo Mirisola curiosamente chegou a ser identificado a essa tendência, por conta de algum tipo de revolta que só pode ser identificada em sua obra se esquecermos que o narrador é importante para a prosa de ficção.5 A tentativa, mesmo equivocada, fornece bom argumento para a afirmação de que os beats voltaram a ser lembrados. No entanto, o que para eles era elemento contextual, no momento histórico em que tal atitude era necessária, chega até agora como... também um elemento contextual! Não houve a transformação em dado formal, o que indica no mínimo duas coisas: os admiradores contemporâneos dos beats não compreenderam os beats e, pior, tornam a história deles uma narrativa banal.

Esse desnível aponta um problema decisivo para a literatura brasileira contemporânea: a imaturidade. Evidentemente, o que era atitude histórica para os beats - aliás, elemento incontornavelmente constitutivo deestética - tornou-se hoje teatralidade.Assim, temos autores que escrevem em veículos de massa fingindo ser marginais, marginais que sabem perfeitamente fazer o papel que a imprensa espera deles e nenhuma desconfiança de que hoje em dia é simplesmente tolo acreditar-se rebelde. De tudo, resta uma espécie de teatro cego em que alguns escritores tentam convencer a platéia de que não estão representando. ${ }^{6}$ Além do espetáculo, o altíssimo custo disso é o mais completo abandono da reflexão, o que evidentemente só pode existir em um país que já esqueceu - sua literatura, ao menos, não se recorda muito bem - que ontem mesmo a lei internacional que proíbe a tortura era uma piada entre nossas autoridades.

O último livro de Marcelo Mirisola, Joana a contragosto7, de novo confirma a forte tendência do autor por formalização do contexto: no caso, o narrador constrói uma espécie de teatro em que irá purgar uma paixão ao mesmo tempo banal e avassaladora. De início, o livro pode passar a impressão de constituir algum ritual interno à obra de transição ${ }^{8}$, já que pela primeira vez o narrador aceita refletir sobre a mesquinharia que o circunda sem se entregar, de imediato e incondicional-
[5] A equivocada filiação também se deve, em parte, a declarações para a imprensa - normalmente toscas do próprio autor, o que demonstra séria fragilidade de nosso meio literário: tendência a utilizar para a crítica meios de promoção mercadológica.

[6] Entre tantos, um bom exemplo disso pode ser a recente publicação de uma antologia de autores que se dizem alcoólatras, como se houvesse algo de historicamente relevante nisso.Cf.Joca Reiners Terron (org.). Uma antologia bêbada. São Paulo: Ciência do acidente, 2004.

[7] Marcelo Mirisola. Joana a contragosto. Rio de Janeiro: Record, 2005.

[8] $\mathrm{Na}$ orelha do livro, eu mesmo cometi o equívoco que, agora, tento sanar. 
[9] Como sugestão, vale lembrar que o procedimento formal desses autores é o mesmo da propaganda - a própria que, em outra chave, elegeu e reelegeu nossos últimos e desastrosos presidentes da República. mente, a ela. No entanto, aos poucos a cena é tomada por um lirismo que, como das outras vezes, capitulará por causa de um desnível de gerações. O amor entre o narrador e uma estudante universitária irresponsável, intelectualmente tosca e com tendência à histeria patética não pode se concretizar porque a garota exige que o autor seja o narrador de seus livros preferidos, exatamente a maneira com que a propaganda tenta vender muitos escritores contemporâneos. Outra vez, o dado histórico transforma-seem esteio formal:como a história deixou de ser narrativa para fazer as vezes de ferramenta formal, o lirismo anunciado naufraga em um terrível desencontro geracional, o mesmo que sempre acontece em momentos de transição radical no cerne de qualquer sociedade. Joana a contragosto não significa nenhuma transformação na estrutura do narrador de Marcelo Mirisola: o conjunto dos livros, cujo atrito entre narrador e contexto chega agora ao auge, é que denuncia uma época de passagem. Por isso, inclusive, alguns capítulos ridicularizam o meio literário paulistano contemporâneo. Não pode haver nada mais kitsch do que escritores reunindo-se para se autocelebrar em intermináveis coletâneas ${ }^{9}$. Transformando o amor, algo exclusivamente privado e íntimo, em espetáculo teatral, Marcelo Mirisola formaliza a produção de máscaras que domina a cena político-cultural brasileira contemporânea, rebaixando a constatação adorniana do lirismo naufragante a um teatro histérico e, muitas vezes, constrangedor. $O$ atrito que forma o narrador, por fim, fica claro nessa denúncia de desníveis: por trás das máscaras contemporâneas, apesar das palmas da violenta máquina de propaganda, não temos histericamente nada. Continuaremos historicamente atrasados, essa é a conclusão da obra de Marcelo Mirisola, se persistirmos em tornar história o que já deveria ser, sem tirar nem pôr, apenas narrativa histórica.

RICARDO LÍsIAS é doutor em literatura brasileira e autor de Duas praças (Globo, 2005). 